\title{
ENTRE SOCIABILIDADES E REPRESENTAÇÕES SOCIAIS: UMA EXPERIÊNCIA ETNOGRÁFICA NA VILA CRUZEIRO DO SUL, PORTO ALEGRE
}

\author{
Ana Patrícia Barbosa ${ }^{1}$
}

\section{Introdução}

O presente artigo apresenta considerações da minha pesquisa de doutorado, a partir da experiência etnográfica realizada na Vila Cruzeiro do Sul, em Porto Alegre, RS, onde busco analisar formas do viver urbano nos diferentes contextos contemporâneos que estabelecem conflitos e arranjos que dimensionam vida social nas modernas sociedades complexas (Velho, 2004), em especial no que se refere aos novos arranjos territoriais das grandes metrópoles brasileiras, dado o contexto de transformações socioespaciais, que se desenha em torno da unidade periferia-cidade, reconfigurando espaços e grupos sociais.

Recorrendo ao método de pesquisa etnográfico, objetivo reconhecer as redes de relações sociais que se formam no interior de uma periferia urbana, com vistas a compreender os arranjos e rearranjos no processo de (re)significação de identidades sociais, onde coexistem espaços e grupos locais diferenciados, porém, estruturados a partir de redes de relações sociais (Foote-Whyte, 2005).

Ao estabelecer este diálogo com esta área de conhecimento e com as técnicas e os procedimentos da pesquisa em antropologia das sociedades complexas (Velho, 1997), é a de proporcionar uma perspectiva interdisciplinar para os estudos sobre o tema em questão, considerando minha formação em Serviço Social, bem como o Programa de Pós-Graduação em Diversidade Cultural e Inclusão Social ${ }^{2}$ ao qual estou vinculada, que tem por objetivo a construção de um corpus teórico específico para a sustentação de um campo de conhecimento interdisciplinar.

A produção interdisciplinar consiste em utilizar o método etnográfico que, apesar de ser um método específico da antropologia, pode ser aplicado, com os devidos ajustes, por outras áreas de conhecimento das ciências humanas. Assim, procuro pontos

\footnotetext{
${ }^{1}$ Universidade Feevale, Brasil.

${ }^{2}$ Programa de Pós-Graduação em Diversidade Cultural e Inclusão Social - Doutorado em Diversidade Cultural e Inclusão Social - Universidade Feevale, Rio Grande do Sul, Brasil.
} 
de ancoragem dos saberes da antropologia, para os estudos interdisciplinares sobre as transformações territoriais de uma periferia urbana na cidade de Porto Alegrem através dos estudos sobre trajetórias sociais, itinerários urbanos e formas de sociabilidades dos moradores de uma periferia urbana na cidade de Porto Alegre/RS.

\section{A Vila Cruzeiro do Sul: invenções e reinvenções de um território}

Localizada na cidade de Porto Alegre, a Vila Cruzeiro do Sul, lócus de minha pesquisa de campo, é uma das mais populosas vilas situada na cidade de Porto Alegre/RS. Localiza-se no território denominado Grande Cruzeiro do Sul, sendo uma das quarenta vilas que compõe a região da Grande Cruzeiro e que estão distribuídas entre os bairros Santa Tereza, Medianeira, Glória, Teresópolis e Nonoai.

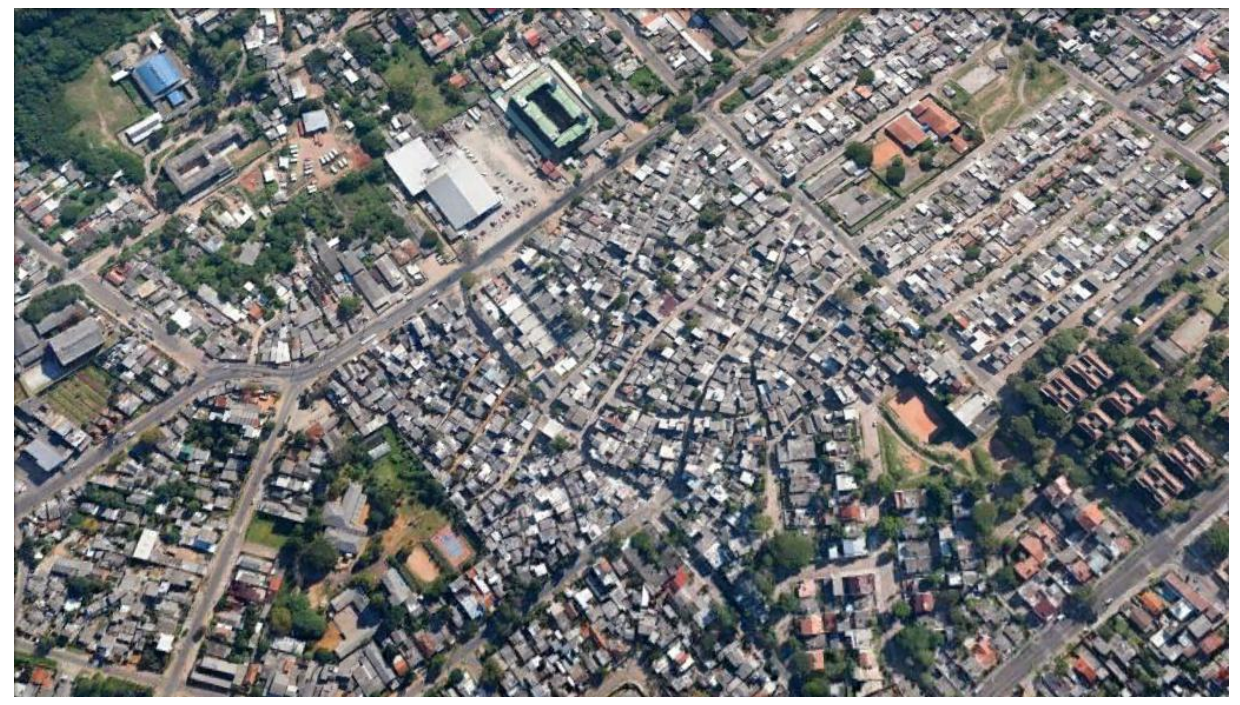

Imagem 1: Vista parcial da Vila Cruzeiro do Sul - divisa com os bairros Cristal e Santa Teresa. Fonte: Google maps.

A população estimada da Grande Cruzeiro é de 200.000 mil habitantes, distribuídos numa área de 200 hectares. Em relação à Vila Cruzeiro do Sul, a população estimada é de 11.394 habitantes. Estimando-se que a população da cidade de Porto Alegre/RS gira em torno de 1.400.000 habitantes, observa-se uma grande 
concentração de moradores na região da Grande Cruzeiro, que perfaz cerca de $15 \%$ da população da cidade, sendo quase a metade dela constituída por crianças e jovens ${ }^{3}$.

Dados do Censo do IBGE de $2010^{4}$ demonstram que no interior da cidade de Porto Alegre existem duas grandes concentrações de baixa renda e baixa empregabilidade, sendo a Vila Cruzeiro uma delas. Trata-se de uma região que, apesar de possuir luz elétrica, água encanada, sistema de esgoto e coleta de lixo, ainda é caracterizada por uma grande concentração de subabitações e com múltiplas carências, que revela, em sua complexidade, a desigual distribuição e consumo de equipamentos urbanos, bem como aspectos das condições de existência dos que ali residem.

A localização geográfica também não contribui com o sistema de escoamento. A Vila Cruzeiro do Sul, assim como as demais vilas que compõem a Região da Grande Cruzeiro, ficam entre morros e, com as chuvas, o lixo é arrastado, contaminando o solo e provocando a obstrução da canalização de esgotos. O sistema de coleta de lixo também é precário, pois algumas ruas são estreitas, o que dificulta a entrada dos caminhões e o lixo acumula-se nas calçadas, conforme se pode observar nas imagens a seguir.

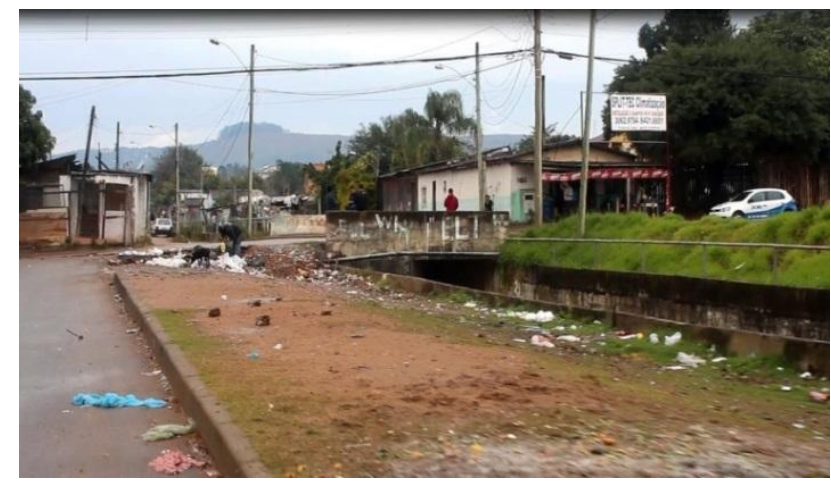

Imagem 2: Acesso à Vila Cruzeiro do Sul pelo bairro Cristal. Fonte: arquivo pessoal.

\footnotetext{
${ }^{3}$ No livro Memórias dos Bairros, os autores Fátima Ávila e Jeferson Rasquim Araújo (2006) apontam que não existem limites geográficos, ou logradouros, que delimite claramente a Região Grande Cruzeiro. Sendo assim, optamos por seguir a pesquisa dos referidos autores e utilizar, neste artigo, a delimitação da Região, a partir do Orçamento Participativo. (Ávila, Fátima, Araújo, Jeferson Rasquim. Vilas da grande cruzeiro. Porto Alegre: Unidade Editirial/SMC, 200).

${ }^{4}$ Fonte: IBGE, 2010. Censo Demográfico de 2010. Fundação Instituto Brasileiro de Geografia e Estatística, dados referentes ao município de Porto Alegre, fornecidos em meio eletrônico.
} 


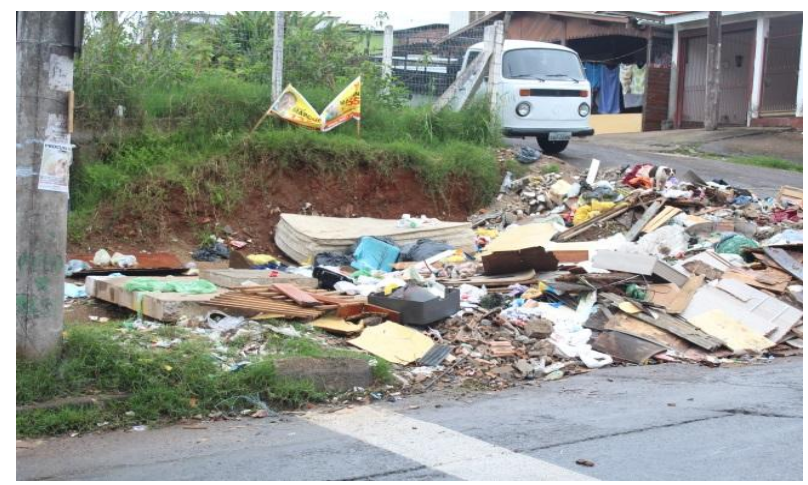

Imagem 3: Vila Cruzeiro do Sul - Esquina da Rua Dona Otília e da Travessa B.

Fonte: arquivo pessoal.

A aproximação inicial com a Vila Cruzeiro do Sul, a partir de minha pesquisa de campo, expressa o sentido secreto desta região, que ganha visibilidade nos meios de comunicação, denotando o que a cidade pensa em relação às pessoas que ali residem. Ao desvendar a realidade vivida pelos moradores de uma periferia urbana, em Porto Alegre, RS, a partir da formação, organização e sistemática de grupos sociais nas cidades, torna-se possível descrever as diferenças que se expressam na própria cidade, demarcando fronteiras internas, com forte dimensão segregativa (Foote-Whyte, 2005; Park, 1987).

Como espaço diferenciado do espaço da cidade e como lócus de exclusão, as periferias criam no imaginário social (Pesavento, 1995), através de suas arquiteturas, seus modos de vida que acabam por conformar identidades e formas de habitar e usufruir do espaço urbano. Assim, as reflexões aqui apresentadas, a partir dos dados coletados no campo, nos levam propor variáveis para a análise sobre as condições de vida dos moradores de periferias, sendo uma delas a dimensão estrutural da territorialidade, no que se refere a este estudo, a Vila Cruzeiro do Sul, na cidade de Porto Alegre.

Esta dimensão pode ser compreendida como consequência da apropriação desigual do excedente urbano, que se concretiza no processo de segregação espacial e onde se refletem os conflitos estruturais, tais como o acesso desigual à urbanização, ao direito à cidade, as desigualdades sociais e econômicas, a negação do direito ao acesso de bens, além do direito à cidadania, por meio dos sistemas de garantia de direitos, a determinados indivíduos e grupos sociais, que geralmente vivenciam situações de vulnerabilidade e risco social. Importante ressaltar que, em particular, a negação aos 
direitos de cidadania a determinados segmentos sociais, em detrimento de outros, achase fortemente associada ao estigma territorial onde tais grupos ou camadas sociais habitam.

Outra variável de análise refere-se à dimensão simbólica, que reflete um conjunto de significações que expressam os conflitos estruturais, tais como os muros reais e simbólicos erguidos nas cidades que demarcam fronteiras entre os bairros e a cidade, entre as vilas e os bairros de camadas médias que cada vez mais são erguidos nas cidades em forma de enclaves residenciais supostamente seguros (Caldeira, 1984; 2000). Essa maneira de viver e sentir a cidade é discutida também por de Cornelia Eckert e Ana Luiza Carvalho da Rocha. Para as autoras, "as mudanças de hábitos coletivos na cidade (dicas de segurança) são precauções apreendidas pelos cidadãos para a diminuição da vulnerabilidade e exposição ao fator de risco evitando atitudes "facilitadoras" de atos criminosos" (2008, p. 6).

Cada vez mais se criam distâncias reais e simbólicas entre os moradores das cidades, as quais podem ser evidenciadas pelo aumento de áreas residenciais fortemente guardadas por guaritas, grades, cercas elétricas, muros, como se fossem ilhas instransponíveis para a circulação da população em geral. Há um muro simbólico que a cidade ergueu e que constantemente é refeito, por força das representações sociais.

Para o caso da cidade de Porto Alegre, as formas assumidas pelas habitações na cidade, em especial nas áreas residenciais das camadas médias urbanas, que vivem próximas da região da Grande Cruzeiro, não é exceção e revela, na sua complexidade, a distribuição desigual dos espaços socialmente construídos e das formas de sociabilidades, que indicam as maneiras como os indivíduos se deslocam, estabelecem aproximações e afastamentos (Simmel, 1987). O que bem pode ser percebido na arquitetura urbana da cidade e bastante visível na região da Grande Cruzeiro, que fica a poucos metros de regiões mais valorizadas da cidade, com a presença de condomínios fechados e de forte esquema de segurança. 




Imagem 4: Condomínio residencial Bairro Santa Teresa. Fonte: Arquivo pessoal.

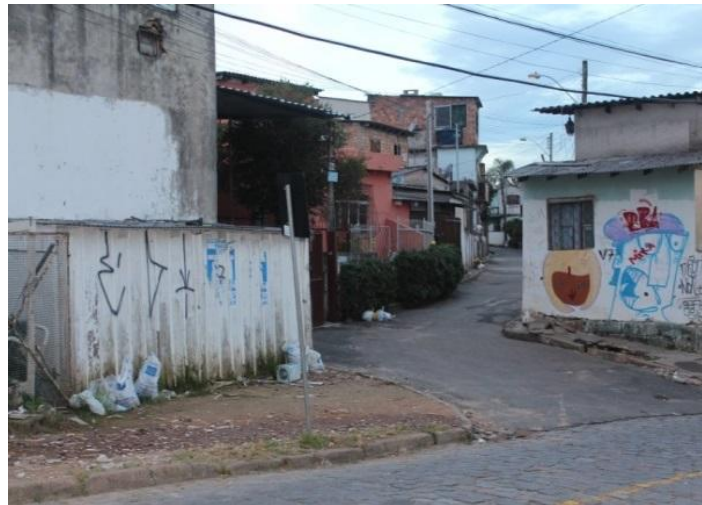

Imagem 5: Condomínio residencial Bairro Santa Teresa. Fonte: Arquivo pessoal.

Na Vila Cruzeiro do Sul, assim como em qualquer periferia do Brasil, a cidade revela-se plural em seus meios, modos e estilos de vida, que acabam por construir distintas formas de socialização, a partir de múltiplos processos de construção de identidades, que traduzem diferentes estilos de vida. Assim, na sequencia deste estudo, apresento o início do meu trabalho de campo na Vila Cruzeiro do Sul, onde procuro retratar as transformações deste território, a partir das redes de sociabilidade e de solidariedade formadas na comunidade, em busca de melhorias nas suas condições de vida.

\section{O Trabalho de Campo}

Em meio ao um território "em guerra" lancei-me, em 2014, na empreitada de realizar um estudo etnográfico na Vila Cruzeiro do Sul. Nos últimos meses esta região tem sido alvo de constantes disputas de gangues rivais de traficantes por pontos de venda de drogas. Frequentemente a mídia veicula manchetes tais como: "Vila Cruzeiro em pé de guerra na Zona Sul de Porto Alegre” 5 , "Após confronto, BM vai intensificar

\footnotetext{
${ }^{5}$ Fonte: Jornal Diário Gaúcho de 18/12/2014 - disponível em: http://diariogaucho.clicrbs.com.br/rs/policia/noticia/2014/12/confronto-entre-gangues-da-vila-cruzeirodeixa-mais-uma-vitima-na-zona-sul-de-porto-alegre-4665888.html
} 
efetivo na Vila Cruzeiro do Sul" ", ou ainda, "Quatro pessoas são presas por tráfico de drogas, na Vila Cruzeiro do Sul, em Porto Alegre” 7.

É neste cenário, de constantes conflitos e tensões, que procuro retratar os desafios de uma pesquisa com um grupo social pertencente às classes populares, que moram em território valorado negativamente no contexto urbano da cidade de Porto Alegre. Desde o início da pesquisa, sabia que minha entrada na Vila Cruzeiro do Sul não seria neutra, pois construir um processo investigativo como prática da pesquisa é uma tarefa que se torna mais complexa, em especial porque o objeto da pesquisa é a vida social, na qual todos estamos inseridos, mesmo que em realidades distintas (Becker, 1997).

Conforme já referido anteriormente, a Vila Cruzeiro do Sul é uma das 40 vilas que compõem a Região denominada Grande Cruzeiro e que neste momento tem sido palco de disputa territorial entre os traficantes da Região, por pontos de venda de drogas. Os traficantes não permitem que os moradores de uma determinada vila andem em outra, assim como a presença de estranhos, em qualquer parte da Grande Cruzeiro, é bastante controlada. Assim, minha presença, na Vila Cruzeiro do Sul, causa estranhamento e desconfortos e não tenho permissão para andar sozinha pelas ruas, nem para conversar com moradores, ou inda para usar filmadora ou máquina fotográfica. Ninguém me chama para dizer o que posso ou não fazer, por onde devo ou não caminhar, mas simbolicamente os recados estão dados, através dos olhares atentos aos meus passos, pela forma como vão, aos poucos, sentando em frente às casas, ou como ficam parados nas esquinas a me observar, ou ainda, através de um motoqueiro que repetidas vezes passa por mim. Ele nada me diz e tão pouco me olha, mas o barulho da moto se aproximando é sinal de estou sendo constantemente acompanhada.

Minha principal preocupação, ao iniciar o trabalho de campo na Vila Cruzeiro do Sul, foi a de criar alguns desconfortos em relação a minha presença ali, tendo em vista o momento de disputa territorial pelo tráfico de drogas. O uso de recursos audiovisuais, tais como máquina fotográfica e filmadora confundem os moradores.

\footnotetext{
${ }^{6}$ Fonte: Jornal Correio do Povo de 07/03/2015 - disponível em: http://www.correiodopovo.com.br/Noticias/550772/Apos-confronto,-BM-vai-intensificar-efetivo-naVila-Cruzeiro-do-Sul

${ }^{7}$ Fonte: globo.com - disponível em: http://www.g1.globo.com/rs/rio.grande.do.sul/bom.dia.rio.grande/videos/t/edicoes/v/quatro-pessoassao-presas-por-trafico-de-drogas-na-vila-cruzeiro-do-sul-em-porto-alegre/334222
} 
Alguns pensam que eu sou jornalista e que ali estou para expor suas vidas, como costumeiramente são retratados nas páginas policiais, através de contornos esteriotipados, tais como bandidos, marginais, miseráveis, dentre outros. Por vezes, preciso esclarecer que o que eu faço ali não irá prejudicá-los ou expô-los de forma negativa, mas sim, que procuro conhecer o lugar onde moram, onde muitos nasceram, cresceram e agora criam seus filhos, a partir de suas histórias e de suas experiências de vida naquela região.

A autorização oficial para minha permanência e deslocamentos se dá através da Presidente da Associação de Moradores da Vila Cruzeiro do Sul (AMOVICS). É com ela que caminhos pelas ruas e becos e, através dela, que vou estabelecendo os primeiros contatos com os moradores. Nosso trajeto foi demarcado pelo do acervo de fotografias que a Associação possui. São imagens do final da década de 70 e início da década de 80, que retratam em território em transformação e onde os moradores se uniram, através de mutirões, em prol de melhorias nas suas condições de vida.

Percorri as mesmas ruas retratadas nas fotografias e conversei com os moradores, entregando-lhes as imagens, que foram meu elo de aproximação inicial com eles. Um apanhando de histórias foi sendo contadas e, através desta interação, um retrato atual da Vila Cruzeiro foi sendo montado, com referências no passado. Alguns se mostraram encantados com as imagens, outros perplexos, ao ver o quanto a rua onde moram se transformou, ao descobrir a casa de um vizinho, um antigo bar, ou mesmo a suas próprias casas. Em meu diário de campo fiz os primeiros registros:

Era uma e meia da tarde, o sol batia forte sobre o asfalto. Um dia quente de primavera, que mais parecia o auge do verão de Porto Alegre. Um calor insuportável! Caminho com a Presidente da Associação de Moradores da Vila Cruzeiro do Sul - AMOVICS pelas ruas da Vila Cruzeiro, pois não tenho permissão para circular sozinha pela região, dados os conflitos recentes pela disputa territorial do tráfico de drogas. Vou escutando seu relato sobre as transformações das ruas, das casas, os mutirões que os moradores fizeram para melhorar as condições de vida na comunidade. Caminhávamos com fotos das décadas de 70 e 80 nas mãos e juntas íamos descobrindo as ruas e casas e observando suas mudanças. Mostrava as fotografias para alguns moradores que encontrei nas ruas. Quanta surpresa e admiração ao verem as imagens! Uns, relembraram tempos passados e me contaram como vivenciaram as transformações na região. Outros pareciam não acreditar que tantas mudanças tinham acontecido ali. Não como negar a emoção que constatei em cada olhar, em cada palavra. Uns iam chamando outros e mostrando as imagens: "olha só", "tu não vai acreditar", "olha a casa da fulana", "olha o bar aqui da esquina como era antes, "olha o fulano na foto"... (Diário de Campo, Porto Alegre, 10/10/2014). 
É neste recorte, de tempo e espaço, onde histórias sobre as transformações do território da Vila Cruzeiro do Sul são contadas, que o uso da linguagem visual, delimita em suas formas simbólicas (Rocha, 1995), o sentido de pertencimento coletivo no que se refere às fotografias da Vila Cruzeiro do Sul, elas sensibilizaram e incentivaram que os moradores falassem sobre a relação que eles estabelecem com o espaço onde habitam, bem contribuíram na sua identificação como parte desta comunidade, conforme revelam as imagens a seguir:

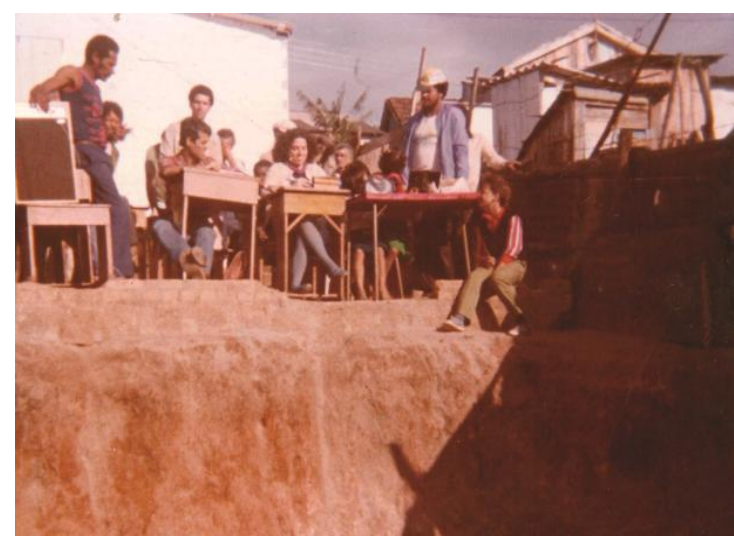

Imagem 6: Assembleia de moradores - 1984. Fonte: acervo AMOVICS.

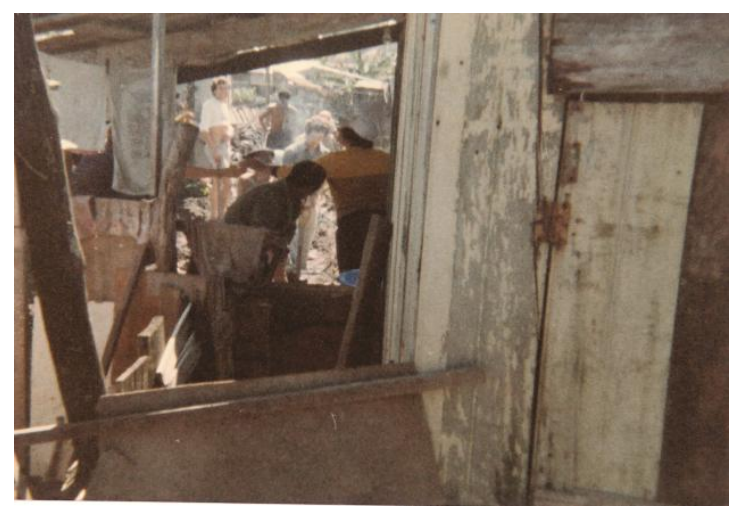

Imagem 8: Mutirão pró-esgoto. Fonte: acervo AMOVICS.

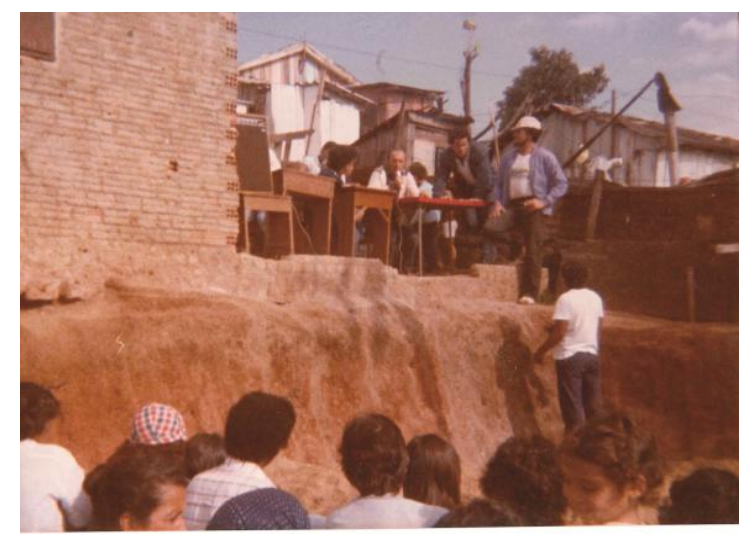

Imagem 7: Assembleia de moradores - 1984. Fonte: acervo AMOVICS.

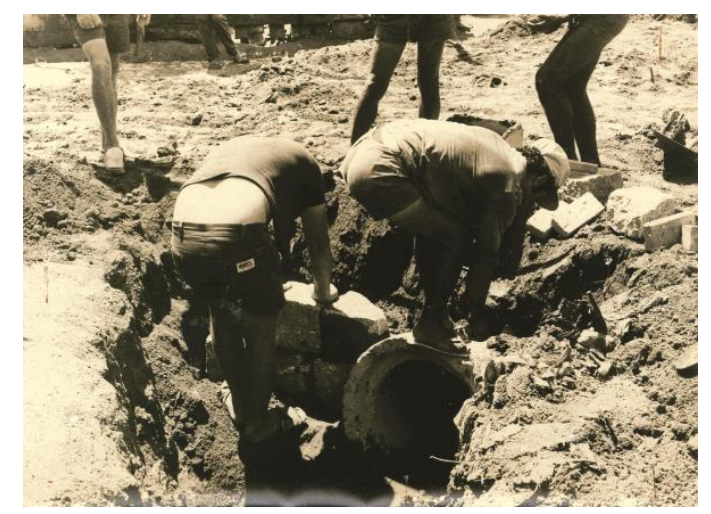

Imagem 9: Mutirão pró-esgoto. Fonte: acervo AMOVICS. 


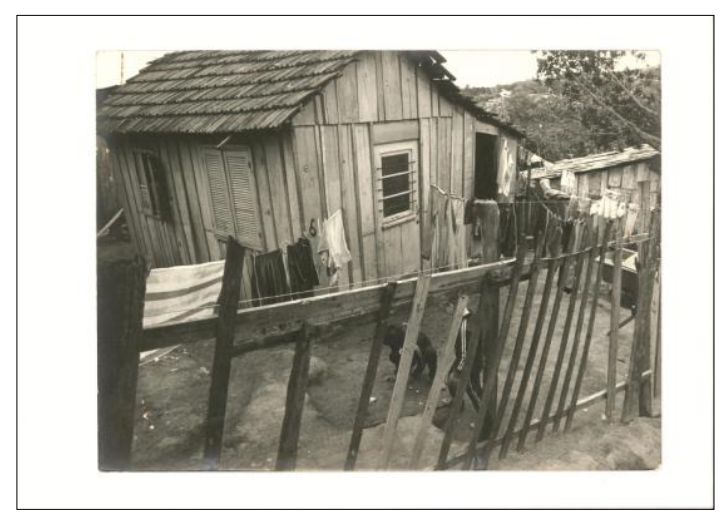

Imagem 10: Casa da Vila Cruzeiro do Sul - 1978. Fonte: acervo AMOVICS.

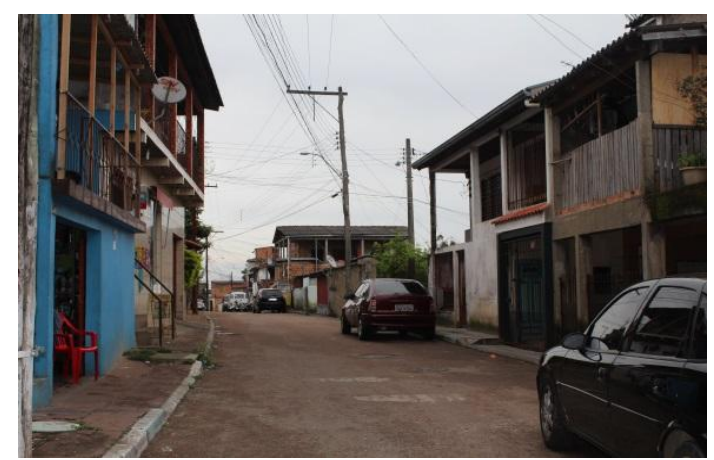

Imagem 12: Casas da Vila Cruzeiro do Sul 2014. Fonte: arquivo pessoal.

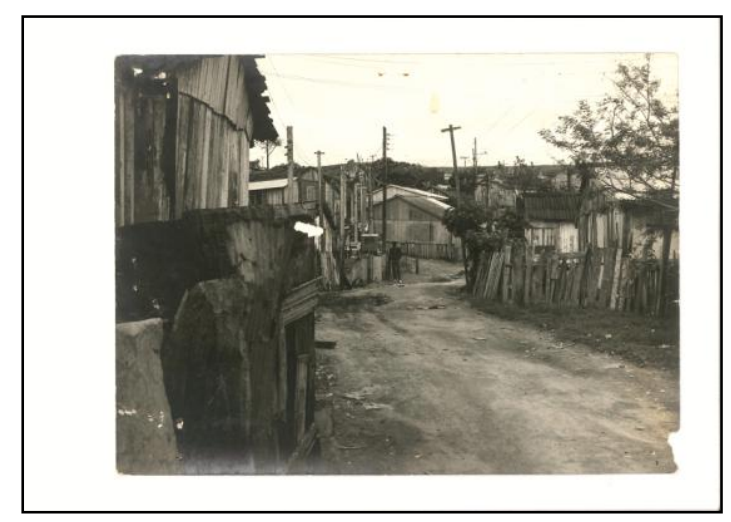

Imagem 11: Casa da Vila Cruzeiro do Sul - 1978. Fonte: acervo AMOVICS.

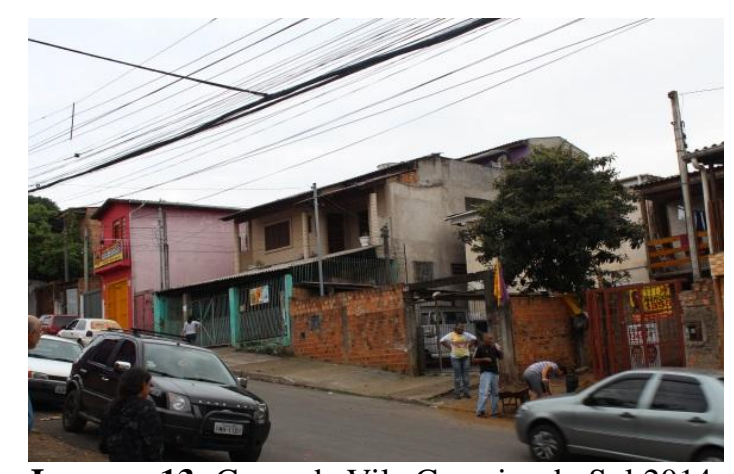

Imagem 13: Casas da Vila Cruzeiro do Sul 2014. Fonte: arquivo pessoal.

As imagens são reveladoras de um território que é espaço de pertencimento, que é fruto das interações entre os sujeitos e que assume papel importante na constituição de grupos sociais. É neste espaço que se encontra o campo de possibilidades, de superação da fragmentação de ações e serviços e onde se evidenciam as carências e as necessidades sociais, mas também onde se forjam, dialeticamente, as resistências e lutas coletivas (De Certau, 1974), como pode ser constato nas imagens e nas narrativas dos moradores da Vila Cruzeiro do Sul. As imagens também são reveladoras da forma como os moradores da Vila Cruzeiro do Sul constroem suas redes de sociabilidades nas quais (re)significam suas ações cotidianas, produzindo distintas formas sociais de ser e estar (Simmel, 1983). 
Em meio as dinâmicas territoriais dos moradores da Vila Cruzeiro do Sul, as contribuições de De Certau (1974), permitem refletir sobre as estratégias e táticas cotidianas que os moradores de periferias empregam para retomar, ou não, suas relações sociais de origem, (re)configurando as suas identidades e pertencimentos, dadas as condições de vida nas grandes metrópoles, que criam formas e necessidades específicas de comportamento. Ou seja, trata-se de evidenciar as lutas significativas, na construção de uma identidade social, onde a periferia torna-se não somente território de espaço físico, mas também código de relações e convívio.

A realidade vivida na Vila Cruzeiro do Sul, em Porto Alegre, RS, revela uma região ainda com graves problemas, mas também um cenário de grandes avanços. Enquanto a região é retratada nas páginas de jornais e nos noticiários de televisão como uma região violenta e perigosa, a cidade esquece que ali vivem pessoas que se consideram felizes, que tem orgulho do lugar onde moram, e que lutam para sobreviver em meio ao descaso das autoridades e ao preconceito da população, o que é possível analisar também neste contexto de um território em "guerra".

Uma das minhas primeiras anotações no diário de campo foi sobre a presença da Brigada Militar (BM) na Vila Cruzeiro. No segundo dia do meu trabalho de campo, uma viatura da BM constantemente passava por mim e os policiais, com a cabeça para fora do carro, me olhavam de cima a baixo. Não há como não se sentir intimida. Essa forma de tratamento não é só dispensada a mim, que ali sou "estranha", mas também as pessoas que residem e que tem seus cotidianos alterados. A BM tem marcado presença constante na região, através de suas viaturas paradas nas esquinas e de seus policiais fortemente aramados, me faço presente.

Conforme minha informante principal, a Presidente da Associação de Moradores, o temor dos habitantes da Vila Cruzeiro é muito maior por causa da polícia, do que pela disputa do tráfico. Sentem-se ameados e reprimidos em suas ações cotidianas. Saem para o trabalho pela manhã e quando voltam à noite, são abordados por policiais que querem saber para onde estão indo e o que fazem caminhando pelas ruas. Muitos são liberados para continuar seus trajetos de volta para casa, após um longo dia de trabalho, somente após serem revistados.

São essas ações que nos fazem perceber uma significativa peculiaridade da cidade em relação à Vila Cruzeiro do Sul, onde a pesquisa esta sendo desenvolvida, que é associá-la à violência e marginalidade, como se a presença da polícia neste local fosse 
proteger a cidade da ameaça constante que esse território e a população que li vive, representa.

Não se trata de negar que na Vila Cruzeiro, assim como nas demais vilas da Região da Grande Cruzeiro, não se tenha problemas de criminalidade, mas trata-se, sim, de refletir que esse não deveria ser o foco das atenções dos governos e da sociedade em geral. Há uma tendência em tornar visível apenas a esfera da criminalização da pobreza e da marginalidade territorial, como parte explicativa do desregramento social, moral e jurídico a que se encontram submetidos os moradores de periferias, afastando-se progressivamente, em alguns aspectos, de uma discussão sobre a precarização dos serviços e equipamentos públicos, na defesa e garantia de direitos à população que vive nas periferias urbanas das grandes metrópoles do Brasil.

A discussão sobre violência ganha amplitude, quando associada às condições das camadas mais pobres dos centros urbanos do país (Wacquant, 2001). Ainda que a pobreza não seja consequência direta da violência, ela não está dissociada ao tema das desigualdades sociais e econômicas, da negação do direito ao acesso de bens, além do direito à cidadania a determinados indivíduos e grupos sociais, que geralmente vivenciam situações de vulnerabilidade e risco social.

Se por um lado, a dimensão segregativa dos moradores da cidade em relação às pessoas que vivem na Vila Cruzeiro do Sul, revela a dimensão da exclusão social que se desenha na cidade, por outro lado, pode ser chave explicativa da união da comunidade por melhorias nas suas condições. A união dos moradores da Vila Cruzeiro do Sul e o seu sentido de pertencimento àquele local está diretamente imbricado com os movimentos sociais, bem como com a criação da Associação de Moradores, que podem ser considerados agregadores da população da Vila Cruzeiro do Sul.

A Região da Grande Cruzeiro conta com uma longa história associativista, onde as associações de moradores tem atuação essencial na organização de vida da comunidade. Em especial, na Vila Cruzeiro do Sul, lócus da pesquisa, os moradores se uniram, abriram, pavimentaram e arborizaram ruas, canalizaram esgotos e criaram o sistema de coleta de lixo. Abriram escolas, creches e igrejas, mas, acima de tudo, construíram seus sonhos, conforme nos relevam em suas narrativas: "o lugar é agente que faz"! (trecho extraído da entrevista com Dona P.S. D, moradora da Vila Cruzeiro do Sul há 50 anos). 
Já faz uns 50 anos que moro aqui e antes era muito ruim. Antes deles tomarem conta da Associação para poder melhorar a vila, depois que a Associação começou ir atrás para melhorar, melhorou muito, ficou muito bom e agora tá melhor ainda, cada vez vai melhorando mais. Antigamente não tinha água, não tinha luz, não tinha nada. Aí depois, mais tarde, começou vir a luz, a água, mas isso com muito trabalho par esse pessoal conseguir. Foi a Associação que trabalhou muito pra arrumar. Antes cada um fazia as casinhas que podiam fazer, depois foi melhorando. Os moradores tinham casa de madeira, agora casa de madeira quase não se vê mais. (Entrevista com Dona P. S. D. - 10/11/2014).



Imagem 14: Travessa B - 1978.

Fonte: acervo AMOVICS.

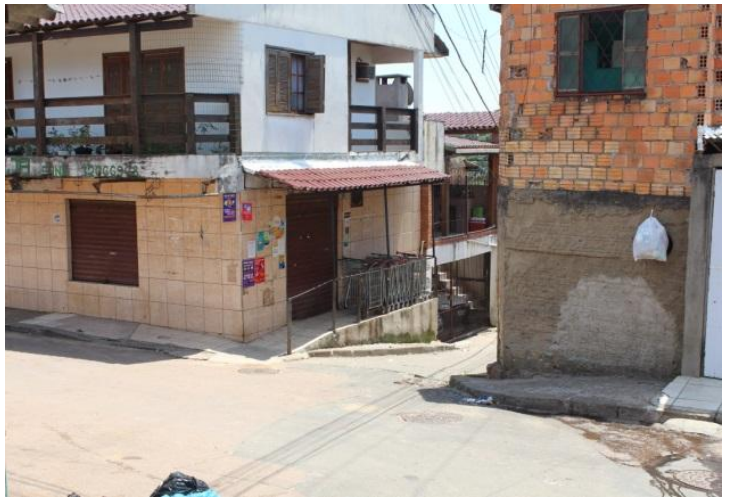

Imagem 15: Travessa B - 2014.

Fonte: arquivo pessoal.

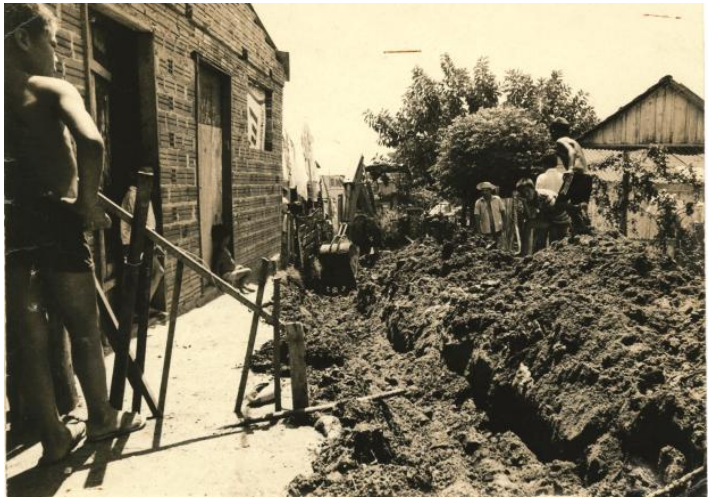

Imagem 16: Travessa $P$ - 1982. Fonte: acervo AMOVICS.

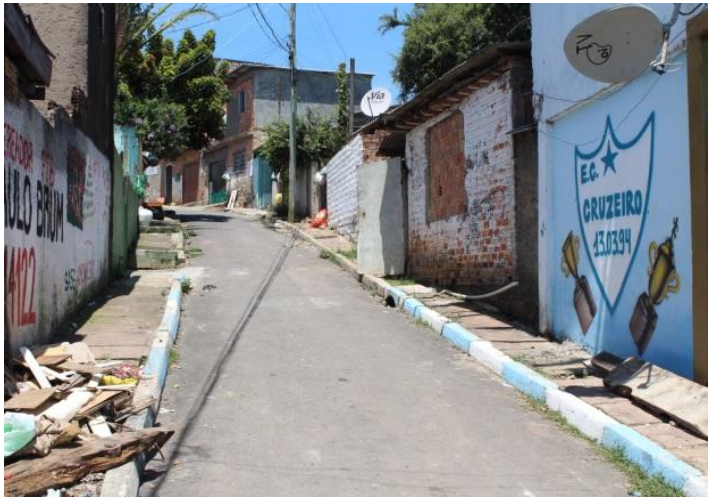

Imagem 17: Travessa $P$ - 2014. Fonte: arquivo pessoal. 


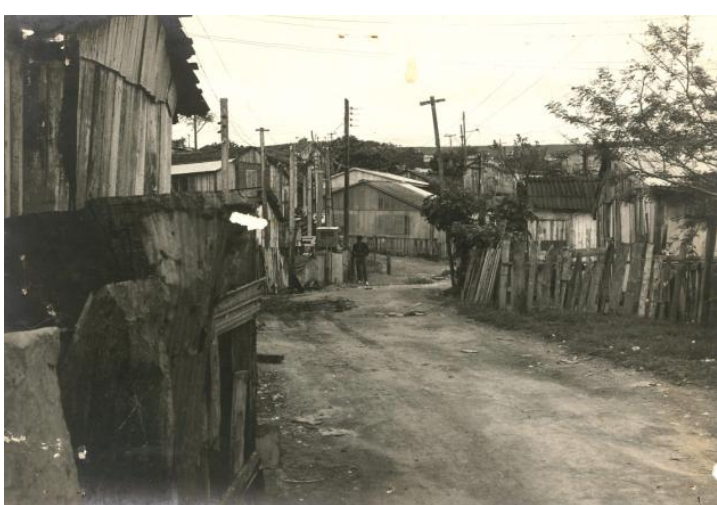

Imagem 18: Rua Padre Lima - 1982.

Fonte: acervo AMOVICS.

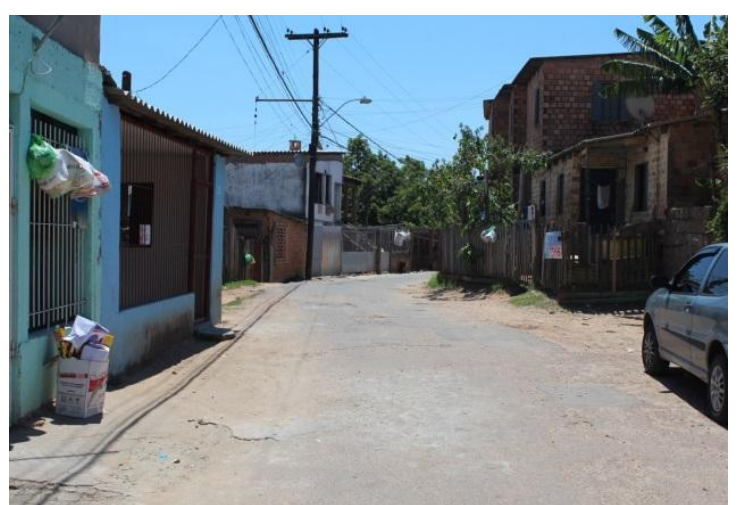

Imagem 19: Rua Padre Lima - 2014.

Fonte: arquivo pessoal.

Na busca por conhecer o território da Vila Cruzeiro do Sul, é possível perceber que ali se encontram indivíduos que embora lidem com significativas restrições financeiras, com carência de alimentos, com moradias precárias, há também uma história de personagens, que apesar da precariedade onde vivem, lutam para sobreviver. E que esta região, que abria muitas famílias, é fruto da (re)invenção, dos afetos, dos sonhos e da solidariedade das pessoas que ali residem. As trajetórias de lutas e de mobilização social dos moradores da Vila Cruzeiro do Sul remontam, através das narrativas, a forma de construção de suas identidades e representam, no meu trabalho de campo, elementos centrais para a rede que vem se constituindo ao longo de minha pesquisa de doutorado.

\section{Considerações finais}

Nesse artigo, o interesse se volta àqueles que vivem em periferias urbanas das grandes metrópoles brasileiras, mais especificamente na Vila Cruzeiro do Sul, em Porto Alegre, RS. O que busquei retratar aqui foi a forma como os moradores desta região construíram formas específicas de sociabilidades, baseadas em lutas coletivas, em união e solidariedade, na busca por melhorias nas suas condições de vida.

Entendo que manter uma vigilância epistemológica é um dos pontos centrais para conduzir a pesquisa, em especial pelo fato de estar tratando de uma construção interdisciplinar, orientada, por diferentes perspectivas e que me faz refletir constantemente sobre o meu papel, enquanto pesquisadora, nesta rede de relações que constituem o universo dos moradores da Vila Cruzeiro do Sul. 
Neste sentido, a etnografia, enquanto metodologia de pesquisa permite essa interação, entre o pesquisador e o seu objeto de estudo, por meio da participação efetiva na realidade investigada (Rocha e Eckert, 2008). Ao estabelecer uma aproximação com método etnográfico, construo também um diálogo com técnicas e procedimentos da pesquisa antropológica, como o diário de campo, a observação participante e o do uso de recursos audiovisuais, como aqui apresentados. Em especial, os recursos audiovisuais, são um componente relevante para os estudos que envolvem questões urbanas, tais como as que pesquiso na Vila Cruzeiro do Sul.

\section{Referências}

BECKER, Howard. Outsiders. Estudo da sociologia do desvio. Rio de Janeiro: Zahar, 2008.

DE CERTEAU, Michel. A invenção do cotidiano. Petrópolis, RJ: Vozes, 1974.

CALDEIRA, Teresa Pires do Rio. A política dos outros. O cotidiano dos moradores da periferia e o que pensam do poder e dos poderosos. SP; Brasiliense, 1984.

FOOTE-WHYTE, William. Doc e seus rapazes. In: Sociedade de Esquina. Rio de Janeiro, Jorge Zahar, 2005.

IBGE. 2010. Censo Demográfico de 2010. Fundação Instituto Brasileiro de Geografia e Estatística, dados referentes ao município de Porto Alegre, fornecidos em meio eletrônico.

LEFEBVRE, Henri. $O$ direito à cidade. Tradução Rubens Eduardo Frias. São Paulo: Centauro, 2001.

PARK, Robert Ezra. A cidade: sugestões para a investigação do comportamento humano no meio urbano. In VELHO, Otávio Guilherme (org.). 4 ed. O fenômeno urbano. Rio de Janeiro: Guanabara, 1987.

PESAVENTO, Sandra Jatahy. Em busca de uma outra história: imaginando o imaginário. Revista Brasileira de História. São Paulo, v. 15, n. 29, 1995.

ROCHA, A. L. C.; ECKERT, Cornelia. Etnografia: saberes e práticas. Iluminuras Revista Eletrônica do BIEV/PPGAS/UFRGS, v. 31, p. 1, 2008.

ROCHA, A.L.C; ECKERT, Cornelia. Etnografia de rua: estudos de antropologia urbana. Porto Alegre: Editora da UFRGS, 2013.

SIMMEL, Georg. Sociologia. Organização de Evaristo de Moraes Filho. São Paulo: Ática, 1983.

SIMMEL, Georg. A metrópole e a vida mental. In: VELHO, Otávio (Org). O fenômeno urbano. Rio de Janeiro, Editora Guanabara, 1987.

VELHO, Gilberto Individualismo e cultura: notas para uma antropologia da sociedade contemporânea. Rio de Janeiro: Zahar, 1997.

WACQUANT, L.J.D. (2001). Os Condenados da Cidade: Estudos sobre marginalidade avançada. Rio de Janeiro, Editora Revan.

DIOGENES, Gloria. A territorialidade e as fronteiras da violência: a dinâmica de formação das gangues urbanas e Grupos identitarios e fragmentação social A violência como marca. In Cartografia da Cultura e da violência. São Paulo, Anna Blume 1998.

DURHAM, Eunice. A sociedade vista da periferia. In: ANPOCS, abril de 1986. Disponível em: http://www.anpocs.org.br/portal/publicacoes/rbcs_00_01/rbcs01_07.htm Acesso em: dezembro de 2014.

FRÚGOLI JR, Heitor. O urbano em questão na antropologia: interfaces com a sociologia. Revista de antropologia. São Paulo: USP, 2005. v 48, no 1.

FRÚGOLI JR, Heitor. Sociabilidade urbana: Rio de Janeiro: Jorge Zahar, 2007. 
MAGNANI, José Guilherme Cantor. Da periferia ao centro: trajetórias de pesquisas em antropologia urbana. São Paulo: Editora Terceiro Nome, 2012.

MEIRELLES, Renato, ATHAYDE, Celso. Um país chamado favela. São Paulo: Gente, 2014.

PEIRANO, M. A favor da etnografia. Rio de Janeiro: Relume-Dumará, 1995.

SANTOS, Milton. Metamorfoses do espaço habitado. São Paulo: Hucitec, 1997.

Santos, Milton. O espaço do cidadão. 6. ed. São Paulo: Studio Nobel, 2002.

VELHO, Gilberto. Projeto e Metamorfose: antropologia das sociedades complexas. Rio de Janeiro: Zahar, 2003.

VELHO, Gilberto. A utopia urbana: um estudo de antropologia social. Rio de Janeiro: Zahar, 1989.

VELHO, Otávio G. (Org). O fenômeno urbano. Rio de Janeiro, Zahar, 1979.

ZALUAR, Alba. A máquina e a revolta. São Paulo, Brasiliense, 1985.

ZALUAR, Alba. "Violência e criminalidade: saída para os excluídos ou desafio para a democracia?", in Sérgio Miceli (org.), O que ler para conhecer o Brasil, vol. I, São Paulo, Anpocs, 1999.

\section{Sites consultados}

https://www.google.com.br/maps/place/Cruzeiro - acesso em 23/08/2014

http://www.observapoa.com.br/ - acesso em 27/07/2014

Recebido em: 23/03/2015

Aprovado em: 19/05/2015 